\title{
UMA RELEITURA DO PAPEL DA PROFESSORA DAS SÉRIES INICIAIS NO DESENVOLVIMENTO E APRENDIZAGEM DE CIÊNCIAS DAS CRIANÇAS
}

\section{Another understanding about elementary teacher's role in kids' development and learning of science}

\author{
Maria Emília Caixeta de Castro Lima ${ }^{1}$ \\ Ely Maués ${ }^{2}$
}

\section{RESUMO}

Em que consiste ensinar ciências para crianças? Que conhecimentos as professoras mobilizam ao ensinar ciências para as crianças? O que é mesmo que elas não sabem e que falta isso lhes faz? Que outros conhecimentos são essenciais para que tenham sucesso no ensino? Por que, mesmo com um suposto déficit de conteúdos conceituais, as professoras conseguem ensinar ciências e possibilitam com isso o desenvolvimento das crianças, preparando-as para etapas posteriores da aprendizagem de conceitos científicos? Como é que nós humanos nos constituímos como sujeitos da cultura? Que relações existem entre os conceitos cotidianos e científicos? Para responder a essas indagações nos aproximamos do ensino de ciências a partir da nossa experiência com professoras das séries iniciais, cotejando esses saberes com a perspectiva histórico-cultural de Vygotsky.

Palavras-chave: Ciências nas séries iniciais, ensino de ciências, séries, conhecimento de conteúdo.

\section{ABSTRACT}

What's really about teaching science to kids? What knowledge do teachers use when they teach science to kids? What do they really don't know and what does its lack can bring? What other knowledge is essential for teaching' success? Why, even with supposed lack of conceptual framework can teachers teach science and allow kids development, preparing them for the incoming steps of scientific concepts learning? How do we human-beings constitute ourselves as cultural subjects? What are the relations between scientific and everyday concepts? To answer these questions we come closer to science teaching by our own experience with elementary teachers, delimiting this knowledge with Vygotsky's cultural-historical perspective.

Key words: primary (or elementary) science, science teaching, content knowledge.

\footnotetext{
${ }^{1}$ Professora da Faculdade de Educação da UFMG, mecdcl@uol.com.br.

${ }^{2}$ Doutorando em educação pela UFMG, Professor do Centro Universitário Izabela Hendrix e Professor da Faculdade Pitágoras.
} 


\section{O (DES)ENTENDIMENTO DAS PROFESSORA SOBRE OS CONTEÚDOS CIENTÍFICOS}

O texto que aqui se apresenta resulta de inquietações que têm nos perseguido há uma década. São dilemas que surgiram quando da primeira vez em que juntos entramos em uma sala de aula para ensinar Fundamentos e Metodologia do Ensino de Ciências para as alunas do Curso de Pedagogia. Professora e monitor com surpresa descobriram quão parcos eram os domínios conceituais das alunas sobre os quais queríamos ensinar os fundamentos e as metodologias de ensino. Nosso esforço foi no sentido de prover as alunas de situações ricas de compreensão dos fundamentos e das metodologias ao mesmo tempo em que procurávamos ensinar os conteúdos conceituais comumente abordados nas séries iniciais. A pergunta que Maués fazia era de como aquelas alunas, tornadas professoras, iriam ensinar o que não sabiam? Quem é a professora que ensina ciências nas séries iniciais? O que ela ensina? Como se ensina ou como ciência deveria ser ensinada para as crianças? O leitor há de convir que, pelas questões levantadas, nunca se esteve em discussão para nós se ciências deveria ou não ser ensinada.

Consideramos hoje que aquelas perguntas, incansavelmente discutidas nos círculos acadêmicos e objeto de investigação e teorização em diferentes artigos e teses, estiveram mal postas. Nossa idéia é a de mudarmos o foco da professora que "não sabe o conteúdo", mas que precisa ensinar, pois tem na sua frente uma turma cheia de crianças e por trás delas a família, a direção da escola e toda a comunidade para exercer a crítica e o controle social do trabalho docente.

A pergunta que procuramos responder aqui é em que consiste ensinar ciências para crianças? Retomamos essas questões objetivando tencionar a discussão em um rumo um pouco diferente do que vem sendo apresentado no meio dos especialistas em ensino de ciências. Com que objetivo se ensina ciências para as crianças? Acreditamos que assim formulando a questão poderemos enriquecer nossa própria compreensão sobre ensinar ciências da natureza nos cursos de Pedagogia e nos espaços de formação continuada de professores de ciências. Acreditamos, também, que a explicitação de nossa compreensão sobre essas questões poderá suscitar em nossos colegas o desejo de polemizar conosco. Assim, estaremos oportunizando a continuidade do debate.

\section{UM BREVE PANORAMA DAS PESQUISAS SOBRE A FORMAÇÃO DE PROFESSORES NAS ÚLTIMAS DÉCADAS}

O ensino nos parece hoje muito mais complexo que no passado devido à crescente demanda por escolarização das camadas populares, aos avanços científicos e tecnológicos no cotidiano, em geral, das mudanças ocorridas nas tecnologias da informação e comunicação e dos desafios do mundo do trabalho. Assim, depois de a ênfase recair sobre os conteúdos a serem ensinados, as questões de sistema e de organização curricular, e sobre os processos de ensino/aprendizagem, convive-se, atualmente, com uma mudança de foco para dar atenção à profissão e ao desenvolvimento docentes.

As pesquisas no campo da formação de professores estão fortemente interessadas em mapear o conhecimento que os professores produzem como condição para um novo profissionalismo. Esses saberes docentes incluem o saber conhecimento -, o saber-fazer - procedimentos e habilidades - e o saber ser - atitudes, crenças e valores morais. TARDIF (2005) chama atenção para dois excessos que se vêm cometendo no âmbito dessas pesquisas: o professor é um cientista e tudo é saber. O fato de considerar o professor como um cientista tem como conseqüência sua inclusão 
numa racionalidade baseada exclusivamente no conhecimento cartesiano, o que é também um equívoco, pois pressupõe que o cientista é, essencialmente, um sujeito racional, epistêmico e isento de valores e crenças pessoais. O segundo excesso está ligado à circunstância de tudo estar se tornando saber docente, o que acaba por colocar essa categoria no vazio, caso não se esteja consciente de todas as filiações, alcances e limites.

Desde a década de 60, do século XX, a formação de professores vem sendo concebida numa perspectiva conhecida pela relação processo/produto, que pressupõe argüir a educação mais pelo viés da funcionalidade do ensino. A pesquisa baseada nesse enfoque está associada ao comportamentalismo, na medida em que procura avaliar a eficácia do ensino estudando a ação docente - processo - e seu impacto na aprendizagem dos estudantes - produto. Passou a ser natural utilizar-se a opinião de alunos, diretores e demais agentes educacionais para se construírem escalas de conceitos de eficácia pela avaliação e classificação do bom professor e de sua prática (Gauthier et al., 1998). A grande ênfase dada à observação em sala de aula ficou a dever à compreensão dos efeitos do ensino nos estudantes.

A pesquisa baseada no enfoque processo/produto esteve limitada, por sua própria natureza, ao desconsiderar a complexidade dos processos de aprendizagem, além de ter servido para criticar os professores e afastá-los da pesquisa acadêmica. Em que pesem as críticas, não se pode negar o mérito dessas pesquisas quando se considera que o comportamento do professor pode estar relacionado ao desempenho do aluno e que o ensino tem uma finalidade em si, que impacta a vida dos estudantes.

Contra esse paradigma dominante, mas ainda se alimentando dele, um outro paradigma teve lugar ao longo dos anos 80 do mesmo século. A pesquisa, até então baseada no behaviorismo, passou a se apoiar num enfoque cognitivista, cujo interesse consiste em compreender as diversas estratégias de ensino, em examinar como os professores em atividade processam informações, promovem mudanças em suas práticas e em tentar formar os professores para a pesquisa-ação, pelo diálogo sobre suas práticas (Gauthier et al., 1998). Em outras palavras, a ênfase passou do estudo do comportamento docente para a cognição em sala de aula. Na educação em Ciências, essa perspectiva foi amplamente utilizada como estratégia de investigação dos processos de ensino/aprendizagem, das concepções prévias dos estudantes, na produção de recursos didáticos e na formação de professores.

Nos últimos 20 anos, as iniciativas relacionadas ao desenvolvimento profissional docente e, mais especificamente, à pesquisa relativa aos saberes e ao saber-fazer têm sido objeto de debate e atenção na educação norte-americana, européia e também brasileira. Iniciou-se um processo de mapeamento do repertório de conhecimentos dos professores mobilizados, quando da realização de seu trabalho, e que abrange os conhecimentos disciplinares, pedagógicos, experienciais, procedimentais e atitudinais. A pesquisa sobre esse repertório de saberes (knowledge base), também chamados de referenciais de competências, foi tomada como pressuposto para fundar a docência numa perspectiva de profissionalização.

Essas pesquisas têm causado impacto, de formas diversas, nas iniciativas de formação de professores. Alguns programas de formação são concebidos e desenvolvidos a partir de uma visão prevalente de competência profissional, definida em termos de desenvolvimento de habilidades pessoais em aplicar categorias do conhecimento especializado para produzir respostas corretas. Se, por um lado, não podemos levar a sério uma visão que se arvora a apontar soluções corretas, explicar tudo e determinar as ações dos professores, por outro, é necessário refletir sobre os inconvenientes em se considerar que nada pode ser dito sobre a sala de aula e sobre a escola em geral dadas as suas complexidades.

O que os professores conhecem? Que conhecimento é essencial para o ensino? Quais práticas, saberes, habilidades e competências aumentam a eficácia no ensino? 


\section{ensaio}

vol $8 \cdot \mathrm{n}^{\circ} 2 \cdot$ dez. 2006

Muitos pesquisadores tentam responder a essas questões de diferentes perspectivas, investigam o planejamento, as decisões interativas, crenças, teorias implícitas, os saberes da experiência, habitus, o conhecimento prático, o conhecimento pedagógico de conteúdo etc. Responder a essas questões significa, de certo modo, identificar um repertório de saberes próprio ao ofício do professor.

Nessa perspectiva, o ensino é visto como a mobilização dos saberes que constituem a base de conhecimento do professor. É desse repertório de saberes que o docente extrai suas certezas, seus modelos simplificadores da realidade, suas razões, argumentos, seus motivos para validar suas ações. É nele que o professor se fundamenta para responder às contingências de seu ofício. Assim, a importância de se constituir um conhecimento de base reside no fato de ele revelar e validar práticas exemplares, permitindo que os professores compartilhem um conjunto de experiências e saberes, o que facilita a socialização profissional. Tendo como referência essa perspectiva, neste artigo, procuramos discutir qual é o conhecimento de conteúdo que uma professora das séries iniciais precisa dominar para ensinar ciências.

\section{A PESQUISA CENTRADA NO ENSINO DE CIÊNCIAS}

Nas duas últimas décadas a pesquisa sobre o ensino de ciências nas séries iniciais vem se intensificando. Há inúmeras investigações sobre concepções espontâneas de alunos e professores, mudança conceitual, perfil conceitual, metodologias de ensino, alfabetização e letramento científicos, inovações curriculares, pesquisas colaborativas de formação de professores etc. É relativamente consensual nessas pesquisas o diagnóstico relativo à baixa qualidade de ensino, quanto à ineficácia das estratégias metodológicas adotadas e, principalmente, sobre o "precário" conhecimento de conteúdo apresentado pelo professores.

Acredita-se que parcela substancial das professoras das séries iniciais não ensina ciências e quando ensinam apresentam baixo entendimento do que estão ensinando (Fumagalli,1998) e pouca confiança em ensinar (Appleton e Kindt, 1992).

$\mathrm{Na}$ nossa experiência como formadores de professores, percebemos que algumas professoras acreditam que não é necessário ensinar tão cedo tais conteúdos. Outras não se sentem autorizadas a ensinar ciências nas séries iniciais. $O$ ato de ensinar ciências gera uma relação de tensão em sala de aula, o que produz nas professoras sentimentos de angústia e aflição, de acordo com relatos delas mesmas. Na disciplina "Fundamentos e Metodologias das Ciências Físicas" de um dos cursos de Pedagogia dos quais somos professores, é freqüente afirmativas como a que se segue:

...começo a me lembrar de fatos que surgiram não só no primeiro dia de aula, mas que foram questões polêmicas discutidas durante o curso: grande parte da turma acreditava que para lecionar Ciências Físicas necessitava primeiramente de saber Ciências. É obvio que um professor precisa ter consciência do que deveria trabalhar com seus alunos. Mas sinto que o pensamento de nós alunos do curso de Ciências Físicas segue a lógica (mesmo que de forma inconsciente) de que: quem conhece Ciências são os biólogos, os físicos, os químicos. Como nós, pessoas "leigas", "não aptas", podemos ensinar ciências?

Além dessa relutância básica dos professores em ensinar ciências, outra constatação é a de que as estratégias predominantemente utilizadas são as exibições de vídeos, a leitura de livros didáticos, o estudo dirigido, o uso de questionários e a escrita de resumos (HARLEN, 1997).

Muitos professores desenvolvem estratégias docentes que lhes proporciona uma sensação de que ensinar ciências pode ser fácil. No caso, costumam apresentar um conjunto de modos de ensinar mais voltado para mecanismos que lhes proporcionam 
tal segurança. São eles: dar menos ênfase aos conteúdos ligados à área de ciências da natureza; optar por conteúdos que têm maior domínio, como são os tópicos relativos aos cuidados com a saúde, com a alimentação ou nutrição e com a higiene (SILVA, 2003); seguir o livro didático passo a passo; preferir as aulas expositivas em vez de fomentar o diálogo e o questionamento das coisas e de seus porquês. Raramente desenvolvem atividades experimentais e quando o fazem revelam que o objetivo dos experimentos é o de clarear as explicações, motivar os alunos para o aprendizado e fixar conceitos. As atividades experimentais surgem como comprovação da teoria, instaurando um divórcio entre a teoria e a prática.

Muitos professores não dominam de fato conceitos básicos de astronomia como as causas do dia e da noite, as estações do ano e a fases da lua, de circuito e corrente elétrica, de que os planetas só podem ser vistos através de telescópios, de que os dinossauros viveram ao mesmo tempo em que viveram os homens das cavernas, que um prego pesa menos que o ferro utilizado como matéria-prima para fazê-lo; que a eletricidade é consumida no interior dos eletrodomésticos e que o norte aponta para o topo do mapa da Antártida. Enfim, apresentam explicações que estão em desacordo com as explicações científicas e se aproximam daquelas dadas por crianças de onze anos, (WebB, 1992 e Jones, 1991, Schoon e Boone,1998).

Do ponto de vista das pesquisas propositivas, salvo algumas exceções, há um esforço para tentar remediar através de propostas metodológicas, inovações curriculares e estudos de casos as dificuldades que os professores apresentam com o conhecimento de conteúdo em ciências. PARKER E HEYwOOd (2000) focalizam suas pesquisas na diferença entre conhecimento e desenvolvimento do entendimento em ciências. A investigação discute as limitações e possibilidades de desenvolver o entendimento sobre ciências através da experiência, reflexão e explicação do professor sobre atividades instrucionais. KeLLY (2000) numa perspectiva construtivista, discute o desenvolvimenta, estrutura e implementação de um curso de metodologia de ensino de ciências para professores primários. Essa autora observou que, após o curso, os professores ganharam novos insights e entendimentos sobre ciências, uma atitude mais positiva frente ao conteúdo e ao ensino de ciências, expressando uma maior confiança em suas habilidades para ensinar.

Smith e Neale (1989) acompanharam um curso de formação em serviço, investigando a mudança no conhecimento de conteúdo dos professores em 16 conceitos relacionados com luz e sombra. Nessa investigação os autores constataram que o conhecimento de conteúdo do professor mudou drasticamente. Eles sugerem que para as pesquisas em desenvolvimento profissional em ensino de ciências pode ser útil considerar o professor das séries iniciais como um adulto aprendiz.

Num caminho próximo, Summers e Kruger, Baseados em suas pesquisas sobre as concepções alternativas das professoras das séries iniciais sobre ciências naturais, têm produzido um extensivo material de desenvolvimento profissional com o objetivo de melhorar o conhecimento de conteúdo sobre ciências do professor das séries iniciais (Summers e Kruger, 1994).

Essas pesquisas evidenciam uma situação desoladora para o ensino de ciências nas séries iniciais. Mas será que o fato da professora ter um conhecimento precário dos conteúdos conceituais de ciências influencia de forma crucial o ensino? Acreditamos que é necessário relativizar os resultados dessas pesquisas. Certamente não podemos ignorar que o conhecimento dos professores das séries iniciais sobre ciências é precário. Mas, ao mesmo tempo, não podemos ficar apenas constatando o que todos nós já sabemos com nossas pesquisas. Será que o único caminho para melhorar a qualidade do ensino de ciências nas séries iniciais é tentar sanar as dificuldades de conteúdo físicos, químicos, biológicos, geofísicos e relativos à astronomia que os professores apresentam? 


\section{ensaio}

vol $8 \cdot n^{\circ} 2 \cdot$ dez. 2006

Alguns autores consideram que é necessário modificar o foco da pesquisa no ensino de ciências nas séries iniciais. Assim, por exemplo, GolbY ET AL. (1995) têm criticado fortemente essas pesquisas argumentando que elas promovem o modelo de déficit do conhecimento do professor. Assumindo que o saber do professor pode ser compensado ou modificado para um conhecimento de conteúdo apropriado e que depois esse pode ser transferido para as crianças, essa linha de pesquisa mais conservadora cria, mesmo que implicitamente, uma concepção transmissiva do ensino e aprendizagem de ciências. Ainda segundo GolBy et al. (1995) seria necessário investigar o que o professor pode fazer, pois somente uma análise focalizada nas capacidades do professor pode nos levar a ter uma expectativa mais realista sobre as práticas do ensino de ciências nas séries iniciais.

Mas até que ponto o domínio de conteúdo de ciências é a saída ou a garantia para que se dê a construção de um ensino de qualidade para a as crianças? Que tipo de conhecimento conceitual uma professora das séries iniciais precisa dominar para ensinar ciências nesse nível de ensino? Será que um bom conhecimento de conteúdos conceituais em ciências é suficiente para garantir um ensino de qualidade nas séries iniciais? Existem pesquisas que indicam que não há diferenças significativas na aprendizagem dos alunos de conceitos científicos ensinados por professores generalistas e professores especialistas (ZuZOvsky, TAMIR E CHEN, 1989). De certo, temos que concordar que problemas relativos ao domínio de conteúdo conceituais existe em todos os níveis, quer seja infantil, fundamental, médio ou superior. Atualmente temos acompanhado um grupo grande de professores de ciências do segmento de $5^{\mathrm{a}}$ a $8^{\mathrm{a}}$ série de física, química e biologia para o ensino médio no Centro de Ensino de Ciências e Matemática de Minas Gerais - Cecimig. Sem surpresa detectamos baixo domínio dos conteúdos conceituais reconhecidos como básicos pelo currículo do Estado de Minas Gerais, o que torna maior o nosso desafio como formadores.

Por outro lado, existem também pesquisas que evidenciam que, embora alguns professores apresentem conhecimento precário de conteúdo, elas conseguem ensinar ciências satisfatoriamente, possibilitando aos seus alunos uma aprendizagem significativa (APPlEton e KIndt, 2002, MAUÉs, 2003 e MAUÉs e VAZ, 2005). Essas pesquisas concluem que, em algumas situações, as estratégias que os professores experientes utilizam para ensinar um conteúdo que lhes é pouco familiar são eficazes para se promover o desenvolvimento e aprendizagem das crianças. Esses professores são capazes de mobilizar saberes das outras áreas de conhecimento (matemática, alfabetização, conhecimentos pedagógicos gerais) para desenvolver atividades significativas, estimulando a criatividade das crianças, favorecendo sua interação com o mundo, ampliando seus conhecimentos prévios, levantando e confrontando os conhecimentos dos alunos. Assim, mesmo não tendo um domínio adequado do conteúdo de ciências, conseguem estabelecer uma mediação de qualidade entre as crianças e os objetos de conhecimento.

\section{AFINAL, AS PROFESSORAS NÃO DOMINAM O QUÊ?}

Quando os pesquisadores e formadores de professores afirmam que as professoras não dominam os conteúdos da área de ciências, por certo, essa fala está voltada para os conteúdos de natureza conceituais. Sendo assim, só nos restaria concluir que as professoras não os tendo, não sabem e não podem ensinar ciências para as crianças. Para avançarmos nessa discussão é preciso ampliar nossa compreensão do que se entende por conteúdos escolares e sobre o que significa ensinar ciências para as crianças.

Entendemos os conteúdos escolares, tal como está apresentado nos PCNs, em suas dimensões conceituais, procedimentais e atitudinais. Os conteúdos conceituais 
se referem à compreensão ou ao domínio dos conceitos científicos. Os conteúdos procedimentais são da ordem do saber fazer, no caso das professoras, do saber ensinar. Os conteúdos atitudinais se referem ao saber ser com as crianças.

Essas pesquisas e projetos de formação inicial e continuada, quando que ressaltam as professoras apresentam um conhecimento de conteúdo precário na área de ciências, estão falando da primeira dimensão dos conteúdos, isto é, a do domínio de conceitos científicos conceituais. Nesse caso, a visão que se tem sobre o papel do ensino de ciências na série iniciais está restrita ao de ensinar conceitos científicos e de que para ensinar basta dominar o conteúdo conceitual. Se estivermos de acordo que é precário o conhecimento dos conteúdos conceituais de ciências das professoras do nível fundamental e que elas devem se ocupar do ensino de conceitos científicos, o único caminho que resta é o de ensinar física, química, biologia e astronomia para elas de modo que tenham um conhecimento especializado sobre essas disciplinas.

Compartilhamos da idéia de que é necessário modificar nosso olhar para a pesquisa no ensino de ciências nas séries iniciais, procurando romper com o modelo do déficit de conhecimento de conteúdo do professor. Contudo, essa mudança não se trata de um recurso para se escamotear o que as professoras não sabem. Não se trata de uma atitude de boa vontade para com os professores das séries inicias ao se retirar o foco do déficit do conhecimento. Essa outra leitura que nos propomos a fazer é uma tentativa de compreender e explicar como, mesmo não tendo o domínio de conceitos científicos, as professores prestam uma grande contribuição à formação de conceitos científicos nas crianças, preparando-as para etapas posteriores da aprendizagem conceitual. Em outras palavras estamos dizendo que o papel dessas professoras no ensino de ciências para as crianças não é o de ensinar conceitos. É outro!

Considerar apenas as dimensões conceituais dos conteúdos significa assumir que o saber do professor ou professora pode ser compensado ou modificado apropriadamente e que, depois disso, pode ser transferido para as crianças. Nesse caso, estamos concordando que a aprendizagem resulta da transmissão de conteúdos conceituais do professor para o aluno. Portanto, consideramos necessário pesquisar o ensino de ciências para as séries iniciais e seus professores recolocando o problema do que significa ensinar ciências nas séries iniciais. Quem são as crianças nesse nível de ensino? E o que as professores precisam saber para mediar o aprendizado das crianças? Trata-se de inverter as perguntas, os referenciais teóricos e o foco do olhar sobre as professoras. No caso, o melhor modo de se fazer isso é olhar com elas (AlmeidA, 2005 e FonTANA, 2000). Em vez de investigar a falta de saber, torna-se necessário investigar o que os professores sabem e precisam dominar de modo mais amplo para lidar com as crianças. Quais são os saberes que possuem? Como esses saberes são mobilizados quando o domínio conceitual lhes falta? Em síntese, investigar nas ações dos professores os conhecimentos que mobilizam quando se deparam com um conceito científico que não conhecem. Que saberes relevantes são esses a serem mobilizados nessas situações? Que estratégias utilizam? Que sentido e importância isso guarda no desenvolvimento da criança?

O discurso sobre os professores guarda uma crença equivocada de que as pesquisas sobre o domínio conceitual fornecem ferramentas ou saberes para uma intervenção autorizada sobre o que se deve ensinar, ser e fazer com as crianças. Ao contrário disso, compartilhamos da idéia de que é preciso construir um outro olhar, de outro lugar para se compreender o fazer e a constituição da professora das séries iniciais. Concluímos com Almeida (2005) que:

O que esse tipo de pesquisa deixa passar despercebido é que a formação de professores, embora possa ser mediada e alavancada pelos formadores em seus cursos e palestras, trata-se de um processo de sujeitos que ao se pensarem são formados, reformados e transformados. Movimento interno mesmo das subjetividades, (Almeida, 2005: 28). 


\section{$\mathrm{ens}_{\mathrm{n} \text { aio }}$}

vol $8 \cdot \mathrm{n}^{\circ} 2 \cdot \operatorname{dez} .2006$

É nesse movimento de se pensarem frente ao conhecimento conceitual, confrontadas com o desafio de estarem cotidianamente com as crianças nos primeiros anos de escolaridade delas é que, intuitivamente, as professoras vão construindo caminhos profícuos para a aprendizagem e o desenvolvimento das crianças.

\section{O QUE ENTENDEMOS POR ENSINAR CIÊNCIAS NAS SÉRIES INICIAIS?}

Para nos aproximarmos de uma resposta para essa pergunta, vamos primeiramente explicitar nossa filiação em VYGOTSKY. Acreditamos que a ação do sujeito sobre o mundo é mediada socialmente pelo outro e pelas ferramentas psicológicas que uma determinada cultura possui. $O$ processo de aprendizagem resulta de uma interação sócio-cultural; é através dos "outros" e da linguagem que nós humanos estabelecemos relações com os objetos de conhecimento. Assim, a sala de aula tornase um espaço de diversas interações, onde a linguagem e os processos de formação de conceitos são elementos fundamentais para a construção compartilhada dos conhecimentos na área de ciências. Nessa perspectiva uma contribuição importante de VYGoTSKY para pensar o ensino de ciências nas séries iniciais é o processo de formação dos conceitos. Segundo VYGotSKY (1991: 50):

"A formação de conceitos é o resultado de uma atividade complexa, em que todas as funções intelectuais básicas tomam parte. No entanto, o processo não pode ser reduzido à associação, à atenção, à formação de imagens, à inferência ou às tendências determinantes. Todas são indispensáveis, porém insuficientes sem o uso do signo, ou palavra".

Nesse sentido, existe uma relação estreita entre o conceito e a palavra. A palavra é o meio pelo qual um conceito é construído, não há conceito sem palavra, a formação dos conceitos só é possível através do pensamento verbal ou do signo. Um conceito nada mais é que uma palavra que expressa uma generalização. Como os significados das palavras se modificam permanentemente na história da humanidade e na história de cada sujeito, podemos afirmar que os conceitos são construções históricas. Surgem e se desenvolvem nas condições concretas da vida humana, não são construtos fossilizados, visto que eles se transformam na dinâmica social carregando as marcas e contradições do momento histórico em que se desenvolveram (FonTANA, 2000).

VYGOTSKY (1991), analisando a aprendizagem e o desenvolvimento infantil no contexto escolar, distingue dois tipos de conceitos que variam pela sua estrutura psicológica e pelo lócus onde tais conceitos são produzidos. VYGOTSKY denominou esses conceitos de espontâneos (cotidianos) e científicos.

Os conceitos espontâneos (fruta, carro, vaca, telefone, computador) surgem da reflexão da criança sobre suas experiências cotidianas, sendo aprendidos assistematicamente. A criança se desenvolve conceitualmente na medida em que consegue relacionar as palavras aos objetos a que se referem, existindo uma prevalência nas relações direto-figuradas. Por esse motivo, a criança não tem consciência de tais conceitos, mesmo que ela conheça bem o conteúdo de um conceito, em geral, não consegue expressá-los verbalmente (LURIA,1979).

Por outro lado, os conceitos científicos (paquiderme, íon, substância, molécula, zoologia, temperatura) se originam em processos formais de ensino e aprendizagem, mediados por atividades estruturadas e especializadas e se caracterizam por formarem um sistema hierárquico de relações lógico-abstratas. Os conceitos científicos disponibilizados no plano social da sala de aula vão sendo incorporados à consciência da criança. Desde o momento em que a criança ouve uma palavra nova (um conceito novo) estão dadas as possibilidades de elas formulem verbalmente tais conceitos. Do ponto de vista psicológico, a principal diferença entre conceitos científicos e espontâneos é que o conceito científico apresenta uma relação de palavras com outras palavras 
enquanto os conceitos espontâneos estabelecem relações mais imediatas de palavras com os objetos a que se referem. Por esse motivo, os conceitos científicos apresentam um sistema hierárquico de inter-relações. Um sistema de relações de generalidade que os conceitos espontâneos não possuem. Essa adjetivação dos conceitos em científicos deve-se ao modo como se estruturam e se relacionam, refere-se às formas hierarquizadas e intrinsecamente comprometidas da conceituação. Nos conceitos científicos a relação do sujeito com o objeto é sempre mediada por um outro conceito e por um outro, esse pode ser um texto, o professor, um adulto qualquer ou que se chama de par mais capaz. A palavra sempre vai à palavra. Um conceito sempre carece de um outro conceito. São redes infinitas de significação que vão se complexificando à medida que nos deparamos com novos sentidos. Nas palavras de VYGotSKY (1987: 219):

O nascimento dos conceitos científicos começa não com um encontro imediato com coisas, mas com um relacionamento mediato para um objeto. Com o conceito espontâneo a criança se move das coisas para o conceito. Com os conceitos científicos ela é forçada a seguir a trajetória oposta - do conceito para as coisas.

Nos conceitos cotidianos ou espontâneos a mediação do adulto acontece naturalmente por meio de observação direta, de manipulação concreta e de vivências pessoais. Diríamos que por convivência e intenção deliberada. Ainda assim, o adulto modifica o ritmo de suas ações para que o aprendiz as acompanhe. Portanto, os conceitos sejam eles espontâneos ou científicos não são incorporados pelas crianças de forma espontânea, mas sempre mediados. São os outros que vão auxiliando a criança a dar sentido ao mundo. Essa mediação social por parte do professor ou de um par mais capaz é ainda mais necessária e mais freqüente no caso dos conceitos científicos que são aprendidos por meio da experiência escolar. O processo de análise e diferenciação ou síntese e integração de conceitos se dá através das interações educativas deliberadas e planejadas.

Os conceitos espontâneos e os conceitos científicos não estão em conflito, embora se desenvolvam em direções opostas, articulem-se dialeticamente e façam parte de um mesmo processo. Segundo VYGOTSKY (1991: 93):

"o desenvolvimento dos conceitos espontâneos da criança é ascendente, enquanto o desenvolvimento dos seus conceitos científicos é descendentes [...] a sua evolução faz com que terminem por se encontrar [...] os conceitos científicos desenvolvem-se para baixo por meio dos conceitos espontâneos; o conceitos espontâneos desenvolvem-se para cima por meio dos conceitos científicos".

Dessa forma, um conceito espontâneo, ao se desenvolver no sentido da abstração, força a sua lenta trajetória para cima, abrindo caminho para a formação e evolução de um conceito científico correlato. O movimento contrário ou descendente dos conceitos científicos cria uma série de estruturas necessárias para a evolução dos aspectos mais concretos e elementares de tal conceito. Podemos dizer que os conceitos espontâneos são os meios para o desenvolvimento dos conceitos científicos.

Daí nossa crença quanto à importância e o direito de todos à posse dos conceitos científicos, pois eles potencializam o desenvolvimento e ressignificam nossas idéias cotidianas ou de senso comum. Como admitimos que a aprendizagem de conceitos científicos é complexa, dá-se a longo prazo e ressignificam o mundo, em nossas indagações sobre o ensino de ciências para as crianças, conforme anunciado anteriormente, jamais colocamos sob suspeita a legitimidade de se ensinar ciências para elas.

As formulações teóricas de VYGOTSKY acerca do desenvolvimento dos conceitos cotidianos e dos científicos implicam o conhecimento dos modos como se postula a relação entre pensamento e linguagem. As palavras que proferimos não comunicam no sentido restrito do termo, nem produzem ou expressam o pensamento. As palavras são a mediação do pensamento. Assim, quanto mais ricos são os modos de dizer e de 


\section{ensaio}

vol $8 \cdot n^{\circ} 2 \cdot$ dez. 2006

explicar o mundo, mais sofisticado e complexo será o pensamento humano. Pensamos e agimos com e pelas palavras. Quando a professora diz "Alice apanhe seu lápis que caiu", Alice age e apanha o lápis ou, por exemplo, pensa e responde: esse lápis não é meu, foi outra pessoa que deixou cair.

Contudo, pensamento e palavra nas crianças estão circunstanciados ao que os conceitos cotidianos permitem associar. Há uma abundância de conexões entre elementos distintos e uma pobreza entre relações lógico-abstratas.

$\mathrm{Na}$ construção de um tal método para o ensino de ciências há que se fazer a análise da estrutura do conhecimento que será mediado e, com base na compreensão das relações de tal estrutura com os níveis de organização da consciência, estabelecer e definir as orientações práticas para o ensino. A análise psicológica do conhecimento é um passo necessário para que se possam reconhecer os níveis de mediação semiótica dos conceitos, sem o que o ensino corre o risco de manter-se, predominantemente, na esfera dos conceitos cotidianos. Esse é o primeiro passo, indispensável, na construção de tal método e não uma tarefa simples, rápida ou pouca. Há muito caminho a percorrer. (Tunes, 2000: 47)

O pensamento verbal ou lógico abstrato destaca-se das relações entre elementos isolados ou empiricamente dados tornando-se expressão conceitual, encarnada em palavras. O papel que a professora exerce no desenvolvimento da criança é justamente o de forçar a ascendência dos conceitos cotidianos, de mediar o processo que vai abrindo caminho para a posse dos conceitos científicos. Como afirmamos anteriormente, o conceito é um ato de generalização, mas como isso é feito no ensino de ciências das séries iniciais? Consideramos que para construir processos de generalização é preciso: observar, classificar, diferenciar, testar, significar, descrever, concluir, teorizar, questionar, comparar, julgar, decidir, levantar hipóteses, discutir, planejar. Fazer isso demanda das professoras saberes ou vivências que não são necessariamente da ordem de conceitos específicos, mas sobre o mundo da criança e de seus modos de pensar, dizer e aprender. Trata-se de um domínio mais da ordem dos conteúdos procedimentais e atitudinais do que conceituais propriamente ditos. Refere-se ao saber ensinar as crianças, de saber ser um par mais capaz para elas, de estar com elas e de conduzi-las a outros patamares de compreensão do mundo. Enfim, de serem capazes de mediar o processo de ascendência dos conceitos cotidianos, de auxiliar as crianças a se desenvolverem.

\section{ENSINO POR INVESTIGAÇÃO NAS SÉRIES INICIAIS}

O ensino de ciências nas séries iniciais tem um papel importante no desenvolvimento, desde que oportunize as crianças expressar seus modos de pensar, de questionar e de explicar o mundo. Nesse caso, o papel do professor é o de um companheiro de viagem, mais experiente nos caminhos, na leitura dos mapas, no registro e na sistematização da experiência vivida. Compartilhamos da idéia de que é possível o ensino de ciências nas séries iniciais como experiência compartilhada. A professora e as crianças vivem uma experiência conjunta como na subida de uma montanha:

Antes de atingir os cumes, a ascensão passa por caminhos muito praticáveis que proporcionam belos pontos de vista, caminhos acessíveis tanto à criança que o descobre como ao adulto que a acompanha. E se este receia tê-los mais ou menos esquecidos ou se os encontram um pouco modificados, pode com prazer descobri-los ao lado de um jovem companheiro (Charpak, 1996: 63).

Nos primeiros encontros das crianças com a aprendizagem de ciências a linguagem científica é introduzida no plano social da sala de aula de modo que todos possam usar as palavras e ir recheando-as de sentido próprio. Nesse momento não há a necessidade de quantificação dos fenômenos por meio de fórmulas e cálculos ou de 
se exigir rígidas estruturações hierárquicas, rigor no uso do conceito ou de se estabelecer múltiplas relações. Para oportunizar o processo de formação e desenvolvimento do pensamento nas crianças, a professora não precisa ter domínio aprofundado dos conceitos em questão. Contudo, há que se ter destreza, disponibilidade e capacidade de propor e orientar os alunos na aprendizagem das idéias que se quer introduzir. Cabe a ela apresentar as idéias gerais a partir das quais um determinado processo de investigação possa se estabelecer procurando selecionar, organizar, relacionar, hierarquizar e problematizar os conteúdos estudados.

O questionamento e a curiosidade são condições necessárias para a aprendizagem em ciências se concordarmos com BACHELARD (1996) que "todo conhecimento é a resposta a uma questão". Uma investigação só faz sentido se ela explicita algo que queremos conhecer. Suscita o interesse e a curiosidade em conhecer ou de inventar um modo de explicar como as coisas funcionam e se articulam. O sujeito que aprende é aquele que se dispõe a significar o mundo e confrontar suas explicações com as dos outros. Essa disposição é da ordem do saber ser e estar no mundo, de se relacionar com os outros, com as idéias próprias e alheias.

As crianças têm grande curiosidade sobre mundo natural. Não se cansam de perguntar o por quê, mesmo que os adultos se mostrem impacientes em respondê-las. Estão sempre disponíveis para testar suas hipóteses e apresentam características importantes para se construir novos conhecimentos. Essa característica do universo em que a criança vive é a chave para a incursão da professora na dimensão procedimental dos conteúdos escolares. Não se quer dizer com isso de um aprendizado que se descola do conteúdo conceitual, mas a favor de uma intervenção qualificada e fortemente orientada pelo saber fazer ou saber procedimental e do saber ser ou atitudinal, conforme os PCN`s.

As crianças nessa fase da vida falam com desenvoltura sobre o que pensam, sem medo ou vergonha de errar. Estão mais desarmadas para ouvir explicações diferentes das delas, ainda que não as compreenda ou concordem com elas. Uma professora que enriquece a sala de aula com a investigação, com a organização do espaço coletivo de participação para o saber falar e ouvir estará educando para o aprendizado de ciências e sobre ciências. No entanto, é comum nos depararmos com situações escolares em que as crianças ficam entregues à sua própria sorte, ficando elas, em última instância, por darem coerência ao fluxo de informação que lhes chegam através de sua interação com o mundo ou proveniente das aulas transmissivas.

Argumentamos a favor de que o ensino de ciências nas séries iniciais se constitua como um espaço rico de vivências. Esse espaço se dá pela intervenção intencionalmente planejada, com objetivos e metas definidas a partir da compreensão do mundo da criança, de suas necessidades e possibilidades. Há que se disponibilizar um conjunto de metodologias privilegiadas para ajudar a criança a construir e organizar sua relação com o mundo material, que as auxilie na reconstrução das suas impressões do mundo real, proporcionando-Ihes o desenvolvimento de novos observáveis sobre aquilo que ela investiga, indaga e tenta resolver.

A ciência possui métodos e teorias, processos e produtos. Os processos da ciência provêm da forma como os conceitos e teorias são construídos, enquanto seus produtos são seus conceitos, teorias, fatos e artefatos tecnológicos. Assim, o conhecimento em ciências não pode ser atribuído somente aos conhecimentos de seus conceitos e fatos. Dessa forma, é fundamental que as crianças, durante sua vida escolar, desenvolvam gradativamente um entendimento da natureza das explicações, modelos e teorias cientificas, bem como das práticas utilizadas para gerar esses produtos. Em outras palavras, todos os estudantes têm o direito de aprender estratégias para pensar cientificamente. É importante que durante o processo de escolarização aprendam a descrever objetos e eventos, levantar questões, planejar e propor soluções, coletar e analisar dados, estabelecer relações entre explicações e evidências, aplicar e 
testar idéias científicas, construir e defender argumentos e comunicar suas idéias.

No ensino de ciências por investigação os estudantes interagem, exploram e experimentam o mundo natural, mas não ficam abandonadas à própria sorte, nem restritos a manipulação ativista e puramente lúdica. A aprendizagem de procedimentos ultrapassa a mera execução de qualquer tipo de atividade e a criança vai adquirindo-a espontaneamente quando possui capacidade intelectual e interesse suficiente (Almeida, 2005).

Situações-problema introduzidas orientam e acompanham todo o processo de investigação, o que permite a construção de novos conhecimentos do que está sendo investigado. Nessa perspectiva o professor desempenha o papel de guia. Ele propõe e discute questões, contribui no planejamento de investigação dos alunos, orienta no levantamento de evidências, auxilia no estabelecimento de relações entre evidências e explicações teóricas, possibilita a discussão e a argumentação entre os colegas, promove a sistematização do conhecimento. Conseqüentemente, o professor oportuniza ao estudante vivenciar suas experiências com parcimônia, na medida em que a construção dos sentidos pessoais é permanentemente confrontada com a significação social das idéias em circulação.

Em síntese, ao conduzir atividades investigativas o professor precisa garantir um ambiente rico de trocas verbais em sala de aula por meio de um intenso e comprometido trabalho colaborativo. Isso requer do professor orientação intencionalmente planejada de modo que permita a liberdade de inventar e propor, sem que isso gere um sentimento de abandono por parte da criança. Sendo assim, consideramos que as atividades investigativas podem desempenhar um importante papel no desenvolvimento das crianças.

\section{CONCLUSÕES}

Acreditamos que modificando nosso olhar para o ensino de ciências nas séries para iniciais, elencando e tomando como referência os saberes das professoras e professores que ensinam ciências, os pesquisadores e formadores estarão em melhores condições para compreender a realidade do ensino de ciências assim, para construírem caminhos juntos.

Há que se considerar que o ensino nas séries iniciais é marcado pela complexidade, pela dificuldade de integrar vários tipos de saberes. O profissional desse segmento necessita conhecer o suficiente sobre diversas áreas do conhecimento, da psicologia ao português, da matemática às artes, das ciências à educação física. Entretanto, ao contrário do que muitos acreditam, ele não precisa ser especialista em cada um desses ramos do conhecimento. O pleno domínio do conteúdo conceitual na verdade, não é acessível a ninguém e nem é necessário ao ensino nas séries iniciais.

Apesar de se esperar que exista uma estreita relação entre segurança para ensinar Ciências e o entendimento do professor sobre Ciências, compartilhamos com outros autores a idéia de que a segurança para ensinar não depende apenas do entendimento de ciências. Basta lembrarmos que existem docentes que possuem um alto entendimento de ciências e baixa segurança para ensinar, do mesmo modo que há professores com elevada segurança para ensinar, mas que apresentam um baixo domínio conceitual.

A polivalência da professora das séries iniciais não consiste numa justaposição de especialidades, mas na capacidade de situar cada disciplina, cada noção, cada conteúdo conceitual, procedimental e atitudinal, ensinado de modo a promover e intensificar o desenvolvimento da criança. Parafraseando FreIrE E HORTON (2003), afirmamos que a especialidade da professora das séries iniciais é saber não ser um 


\section{ensaio}

vol $8 \cdot \mathrm{n}^{\circ} 2 \cdot \operatorname{dez} .2006$

especialista. Essa característica da professora permite um olhar mais integrador, uma posição diante do conhecimento que muitas vezes supera o modelo disciplinar.

Para finalizar é bom esclarecer que não quisemos com esse texto retomar velhas crenças da década de 60 , do século passado quando se acreditou que deveríamos estimular atitudes científicas nas crianças, com o intuito de apresentar a elas um modo seguro de se fazer ciência ou disseminar uma falsa idéia de que as teorias emergem dos dados empíricos, do sensível e imediato. Foram anos de crença de que a educação deveria investir na formação de cientistas e que tal formação ocorreria praticando-se 0 tal método científico. Muito dessas crenças ainda residem nos discursos dos professores em geral, de quaisquer níveis de ensino que sejam.

A investigação ou problematização do mundo não se restringem ao que pode ser experimentado e comprovado empiricamente. Investigação não se restringe à experimentação. Trata-se muito mais de uma atitude e de um modo de argüir o mundo. Isso é próprio da ciência e dos cientistas, o que aproxima as pessoas de um outro modo de pensar e de explicar para além das crenças e dogmas. Daí a importância das professoras perceberem a necessidade de se introduzir atividades investigativas no plano social da sala de aula. Reconhecerem a importância do desenvolvimento de procedimentos relacionados à inventividade científica, à emissão de hipóteses e a interpretação dos resultados, à argumentação lógico-abstrata e à comunicação de idéias, bem como de se fortalecer as atitudes de dúvida, tolerância, colaboração, comunicação das idéias, etc. Isso não é pouco e as professoras sabem e podem fazer.

Assim, o grande desafio para as professoras das séries iniciais e para nós, formadores, é superar a crítica do déficit do domínio conceitual e colocar em outros patamares as necessidades formativas dos professores e professoras que formamos. Compreendermos melhor quem é a criança e o que significa ensinar ciência para elas e para os professores delas. Para as professoras o desafio é o de acreditarem que podem e sabem ensinar ciências para as crianças. Recuperarem sua auto-estima e planejar aulas ricas de sentidos em circulação. 


\section{ensaio}

vol $8 \cdot \mathrm{n}^{\circ} 2 \cdot$ dez. 2006

\section{REFERÊNCIAS BIBLIOGRÁFICAS}

ALMEIDA, Sheila Alves. Ver o invisível: o olhar das professoras sob uma experiência de ensinar e aprender com as atividades de conhecimento físico nos ciclos iniciais. 2005. Dissertação de Mestrado. Belo Horizonte: Faculdade de Educação da UFMG, 2005.

APPLETON, K.; KINDT, I. Why teach prymary science? Influences on beginning teacher's practices. International Journal of Science Education, v. 14, n. 5, p. 491-503. 1992.

APPLETON, K.; KINDT, I.. Beginning elementary teachers' development teachers of science. Journal of Science Teacher Education, 13, 43-61. 2002.

BACHELARD, Gaston. A formação do espírito científico: contribuição para uma psicanálise do conhecimento. 3 ed. Rio de Janeiro: Contraponto. 1996. 316 p.

CARVALHO, Ana Maria P.; GONÇALVES, Maria Elisa et al. Ciências no Ensino Fundamental: o conhecimento físico. São Paulo: Scipione, 1999.

CHARPAK, Georges. As ciências na escola primária: uma proposta de ação. Sintra/ Portugal: Inquérito, 1996.

FREIRE, Paulo; HORTON, Myles. O caminho se faz caminhando: conversas sobre educação e mudança social. Petrópolis, RJ: Vozes, 2003. p. 232.

FONTANA, R. A.C. A mediação pedagógica na sala de aula. 3 ed. Campinas: Autores Associados, 2000, 176 p.

FUMAGALLI, Laura. O ensino de ciências naturais no nível fundamental de educação formal: argumentos a seu favor. In: WEISMANN, Hilda (Ed.). Didática das Ciências Naturais. Porto Alegre: ArtMed, 1998.

GAUTHIER, C. et alli. Por uma teoria da pedagogia - pesquisas contemporâneas sobre o saber docente. Ijuí: UNIJUÍ, 1998.

GOLBY, M. e MARTIN, A. e PORTER, M. Some researches' understanding of primary teaching: comments on Mant and Summers' "Some primary-school teachers" understanding of the Earth's place in the universe'. Research Papers in Education, Vol. 10, n. 3, $297-302,1995$.

HARLEN, Wynne. Primary Teachers' Understanding of Concepts of Science: impact on confidence and teaching. Int. J. SCI EDUC. Vol. 19, n.1, 93 - 105, 1997.

JONES, B. Pre-service elementary teachers' explanations of diurnal, seasonal and lunar phenomena. Unpublished paper, University of Tasmania School of Education, Austrália.

KELLY, Janet. Rethinking the Elementary Science Methods Course: a case for content, pedagogy and informal science education. Int. J. SCI EDUC. Vol. 22, n.7, 755 - 777, 2000.

LÚRIA, A. R. Curso de Psicologia Geral. 1. ed. Rio de Janeiro: Civilização Brasileira, 1979. v. 4. 


\section{ensaio}

vol $8 \cdot \mathrm{n}^{\circ} 2 \cdot \operatorname{dez} .2006$

MAUÉS, Ely. Ensino de Ciências e Conhecimento Pedagógico de Conteúdo: narrativas e práticas de professoras das séries iniciais. 2003. Dissertação de Mestrado. Belo Horizonte: Faculdade de Educação da UFMG, 2003.

MAUÉS, Ely; VAZ, Arnaldo. Conhecimento pedagógico de conteúdo geral e o conhecimento de conteúdo de ciências das professoras das séries iniciais. In: Encotro Nacional de Pesquisa em Educação em Ciências 5, Bauru. Anais e Cd. São Paulo, 2005.

PARKER, Joan; HEYWOOD, Dave. Exploring the Relationship Between Subject Knowledge and Pedagogical Content Knowledge in Primary Teachers' learning about forces. Int. J. SCI EDUC. Vol. 22, n.1, 89 - 111, 2000.

SCHOON, Keneth; BOONE, William. Self-efficacy and alternative conceptions of science of preservice elementary teachers. Science Education, Vol. 82, n. 5. p 553 - 568. 1998.

SILVA, Nilma Soares. O repertório de conhecimentos de um grupo de professores de ciências específicos ao ensino de química no nível fundamental. Dissertação de mestrado. Faculdade de Educação da UFMG, 2003.

SMITH, Deborah C.; NEALE, Daniel C. The construction of subject matter knowledge in primary science teaching. Teaching \& teacher education.

SUMMERS, M.; KRUGER, C. A longitudinal study of a constructivist approach to improving primary school teachers' subject matter knowledge in science, Teaching and Teacher Education, v. 10, n. 5, 499-519, 1994.

TARDIF, Maurice . Saberes docentes e formação profissional. 5ª̣ed. Petrópolis: Editora Vozes, 2005.

TUNES, Elizabeth. Os conceitos científicos e o desenvolvimento do pensamento verbal. Cadernos CEDES. nำ35. 36- 49, 2000.

WEBB, Paul. Primary Teachers' Understanding of Eletric Current. . Int. J. SCI EDUC. Vol. 14, n.4, 423 - 429, 1992.

VYGOTSKY, L. S. Pensamento e Linguagem. 3ed. Rio de Janeiro: Martins Fontes, 1991.

VYGOTSKY, L. S. Thinking and speech. In: Collected works of L. S. Vygotsky. New York: Plenum, 1987.

ZUZOVSKY, R.; TAMIR, P.; CHEN, C. Specialized science teachers and general teachers and their impact on student outcomes. Teaching and teacher education. Vol. 5, n. $3 p$ 229-242.1989.

Data de recebimento :05/09/2006

Data de aprovação: 30/11/2006 